\title{
Analysis of the association of the expression of KiSS-1 in colorectal cancer tissues with the pathology and prognosis
}

\author{
XINKAI HUO ${ }^{1 *}$, LEI ZHANG ${ }^{2 *}$ and $\mathrm{TAO} \mathrm{LI}^{3}$ \\ Departments of ${ }^{1}$ Gastrointestinal Surgery, ${ }^{2}$ Anorectal Section and ${ }^{3}$ Oncology, \\ Dezhou People's Hospital, Dezhou, Shandong 253014, P.R. China
}

Received July 28, 2017; Accepted November 29, 2017

DOI: $10.3892 / \mathrm{ol} .2017 .7630$

\begin{abstract}
Colorectal cancer is a common malignant tumor of the digestive tract with high morbidity and mortality rates. The aim of the present study was to examine the expression level of KiSS-1 in tumor tissues of patients with colorectal cancer, and to explore the relationship with the clinicopathology and prognosis of patients with colorectal cancer. Frozen tumor tissue and corresponding cancer-adjacent normal tissue specimens were selected from 56 patients with colorectal cancer who were treated in the Department of Surgery of our hospital from May 2009 to December 2011. The expression levels of KiSS-1 messenger ribonucleic acid (mRNA) in tumor tissues and cancer-adjacent normal tissues were detected by reverse transcriptase-quantitative polymerase chain reaction (RT-qPCR). The expression levels of KiSS-1 proteins in colorectal cancer tissues and cancer-adjacent normal tissues were further detected by immunohistochemistry. In addition, the association of the expression level of KiSS-1 proteins in tissues of colorectal cancer patients with pathological parameters and the prognosis of patients with colorectal cancer was analyzed combined with clinical data. The RT-qPCR results showed that the expression of KiSS-1 mRNA in colorectal cancer tissues was significantly lower than that in cancer-adjacent normal tissues $(\mathrm{P}<0.05)$. Immunohistochemistry results indicated that the positive expression rate of KiSS-1 proteins in colorectal cancer tissues $(26.79 \%)$ was significantly lower than that in cancer-adjacent normal tissues (80.36\%). The low expression of KiSS-1 in colorectal cancer tissues was associated with the degree of differentiation, invasion and metastasis, as well as clinical staging. The 5-year overall survival rate of patients with colorectal cancer was $55.36 \%$ (31/56). The univariate survival
\end{abstract}

Correspondence to: Dr Tao Li, Department of Oncology, Dezhou People's Hospital, 1751 Xinhu Street, Dezhou, Shandong 253014, P.R. China

E-mail: lw22s2@163.com

*Contributed equally

Key words: colorectal cancer, KiSS-1, pathological parameters, prognosis analysis showed that patients with lowly expressed KiSS-1 had worse prognosis. The low expression of KiSS-1 is closely associated with the occurrence and development of colorectal cancer, especially to the degree of differentiation, invasion and metastasis, as well as clinical staging. Thus, the expression of KiSS-1 in colorectal cancer tissues can be used as a reference for the prognosis of colorectal cancer, and KiSS-1 is a potential new target for the treatment of colorectal cancer.

\section{Introduction}

Colorectal cancer is a common malignant tumor of the digestive tract, with high morbidity and mortality rates. Its incidence ranks fourth in malignant tumors in China, and the mortality rate ranks fifth in tumors leading to death (1). In addition, the incidence and mortality rates of colorectal cancer in China are on the increase, which has deleterious effects on the lives and health of patietns (2). Previous findings have shown that the 5-year survival rate of colorectal cancer patients with metastasis was significantly lower than that of colorectal cancer patients without metastasis $(3,4)$. In the diagnosis of patients with colorectal cancer, metastasis occurs in approximately $25 \%$ of patients, which is the main reason leading to the poor curative effect in the clinical treatment for patients (5).

Metastasis suppressor and promoter genes play key roles in the process of tumor metastasis. An increasing number of scholars have been focused on the study of tumor metastasis suppressor genes. A previous study demonstrated that the effect of metastasis suppressor genes on tumor metastasis is more critical than that of metastasis promoter genes, and the reduction in the expression of metastasis suppressor genes or gene loss may induce the invasion and metastasis of tumor cells (6). The KiSS-1 gene was initially identified in non-metastatic melanoma cells, and is an important tumor metastasis suppressor gene (7). KiSS-1 genes are located at the long arm of human chromosome 1, and the gene encoding proteins can bind to the $\mathrm{G}$ protein-coupled receptor 54 (GPR54), resulting in physiological effects of inhibition of the proliferation, invasion and metastasis of tumor cells and induction of the differentiation and apoptosis of tumor cells (8). Further findings have shown that the expression level of $\mathrm{KiSS}-1$ genes is downregulated in a variety of tumors, including pancreatic (9), gastric (10), breast (11) and bladder cancer (12), and promotes tumor invasion and metastasis. 
The findings of Siegel et al indicated that the expression level of KiSS-1 proteins in the tumor tissues of patients with colorectal cancer was significantly lower than that in the normal colorectal tissues. Additionally, KiSS-1 acts as a tumor suppressor gene in the occurrence and development of colorectal cancer (13).

The present study aimed to investigate the expression of KiSS-1 in the tumor tissues of patients with colorectal cancer and its effects on pathological parameters and the prognosis of patients with colorectal cancer. Reverse transcription-quantitative polymerase chain reaction (RT-qPCR) and immunohistochemistry were used to analyze the expression levels of KiSS-1 in the tumor tissues and cancer-adjacent normal tissues of patients with colorectal cancer. The effects of KiSS-1 expression on pathological parameters and the prognosis of patients with colorectal cancer were analyzed combined with clinical data.

\section{Materials and methods}

Data. For the clinical data, 56 patients with colorectal cancer treated in the Department of Surgery of our hospital from May 2009 to December 2011 were selected. The patients

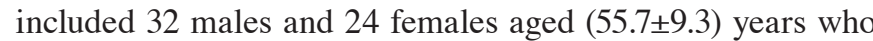
received surgical treatment for the first time, and had no history of chemotherapy and radiotherapy. Tumor tissues and canceradjacent normal tissues $>10 \mathrm{~cm}$ away from the tumor were taken from the patients with colorectal cancer during surgery. A section of the tissues was immediately stored in liquid nitrogen, while the other section was fixed in $10 \%$ neutral formalin solution. The patients were diagnosed with colorectal cancer via pathological analysis. The study was approved by the Medical ethics committee of the Dezhou People's Hospital (Shandong, China). All the patients or their family members signed the informed consent.

The main reagents used were TRIzol, reverse transcription and RT-qPCR kits (Invitrogen, Carlsbad, CA, USA); primer synthesis [Takara Biomedical Technology (Dalian) Co., Ltd., Dalian, China]; rabbit anti-human KiSS-1 polyclonal antibody (18375-1-AP), general immuno histochemical test kit for anti-rat/rabbit (KIHC-1) (Wuhan Sanying Biotechnology Co. Ltd., Wuhan, China), glyceraldehyde-3-phosphate dehydrogenase (GADPH) antibodies, horseradish peroxidase (HRP)-labeled antibodies (Wuhan Proteintech Group, Inc., Wuhan, China); and immunohistochemical staining kit SP-9001 (Beijing Zhongshan Golden Bridge Biological Technology Co., Ltd., Beijing, China).

Detection of the expression of KiSS-1 messenger ribonucleic acid (mRNA) in tissue specimens of patients by RT-qPCR. Total RNA in the frozen tissues of patients was extracted using TRIzol kits, and RNA concentration and purity were measured using an ultraviolet spectrophotometer (Hitachi, Tokyo, Japan). When the ratio of A260/A280 was between 1.8 and 2.0, the samples were considered to be qualified. Reverse transcription was conducted according to the protocol. PCR was carried out according to the recommended method of RT-qPCR kits with the obtained complementary deoxyribonucleic acid (cDNA) as the template. Primer sequences are shown in Table I. Specific reaction conditions were: pre-denaturation at $94^{\circ} \mathrm{C}$ for
Table I. Primer sequences of RT-qPCR.

\begin{tabular}{lc}
\hline Gene name & \multicolumn{1}{c}{ Primer sequence } \\
\hline KiSS-1 & F: 5'-ACCTGGCTCTTCTCACCAAG-3' \\
& R: 5'-TAGCAGCTGGCTTCCTCTC-3' \\
GAPDH & F: 5'-GCACCGTCAAGGCTGAGAAC-3' \\
& R: 5'-TGGTGAAGACGCCAGTGGA-3'
\end{tabular}

F, forward; R, reverse.

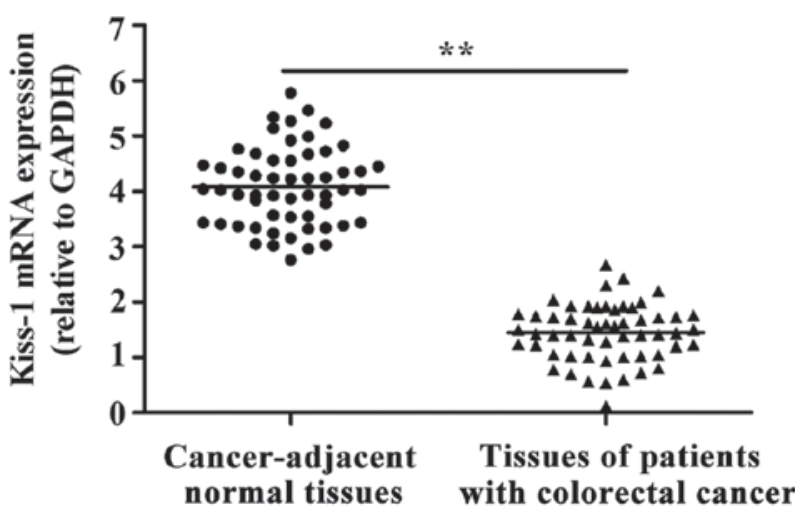

Figure 1. Detection of the expression of KiSS-1 in tissues of patients. The expression of KiSS-1 mRNA in tissues of patients with colorectal cancer is significantly decreased compared with that in cancer-adjacent normal tissues; ${ }^{* *} \mathrm{P}<0.01$.

$5 \mathrm{~min}$, denaturation at $95^{\circ} \mathrm{C}$ for $30 \mathrm{sec}$, annealing at $60^{\circ} \mathrm{C}$ for $30 \mathrm{sec}$, and extension at $72^{\circ} \mathrm{C}$ for $30 \mathrm{sec}$ and the amplification was conducted for 30 cycles. With GAPDH as the control, the expression level of KiSS-1 mRNA was calculated using the relative quantification method. The formula used was: $\Delta \mathrm{Ct}$ (target gene) $=\mathrm{Ct}$ (target gene) $-\mathrm{Ct}$ (control gene)

Detection of the expression of KiSS-1 proteins by immunohistochemistry. Tissues fixed in 10\% neutral formalin solution were taken and embedded in paraffin, and then continuously cut into $4-\mu \mathrm{m}$ slices. Immunohistochemical staining was performed by streptavidin-perosidase (SP) two-step method, and the procedures were carried out according to the protocol of the kits. Routine dewaxing was performed, citric acid solution was used for repairing protein, and goat serum was applied for sealing. KiSS primary antibodies (diluted at 1:200) were added drop by drop, and the tissues were incubated in a refrigerator at $4^{\circ} \mathrm{C}$ overnight. After washing by pre-cooling phosphate-buffered saline (PBS) solution three times, secondary antibodies (diluted at 1:1,000) were added drop by drop. The tissues were incubated at room temperature for $30 \mathrm{~min}$ and washed by pre-cooling PBS three times. Diaminobenzidine (DAB) development was then conducted, hematoxylin was used for re-dyeing, and finally gum was used for mounting.

Five $\mathrm{x} 400$ visual fields were randomly selected from each slice. Results of KiSS-1 protein-positive staining were that pale brown and chocolate-brown particles were precipitated in the cytoplasm. According to the percentage of stained cells and the staining intensity, scores were evaluated comprehensively: 

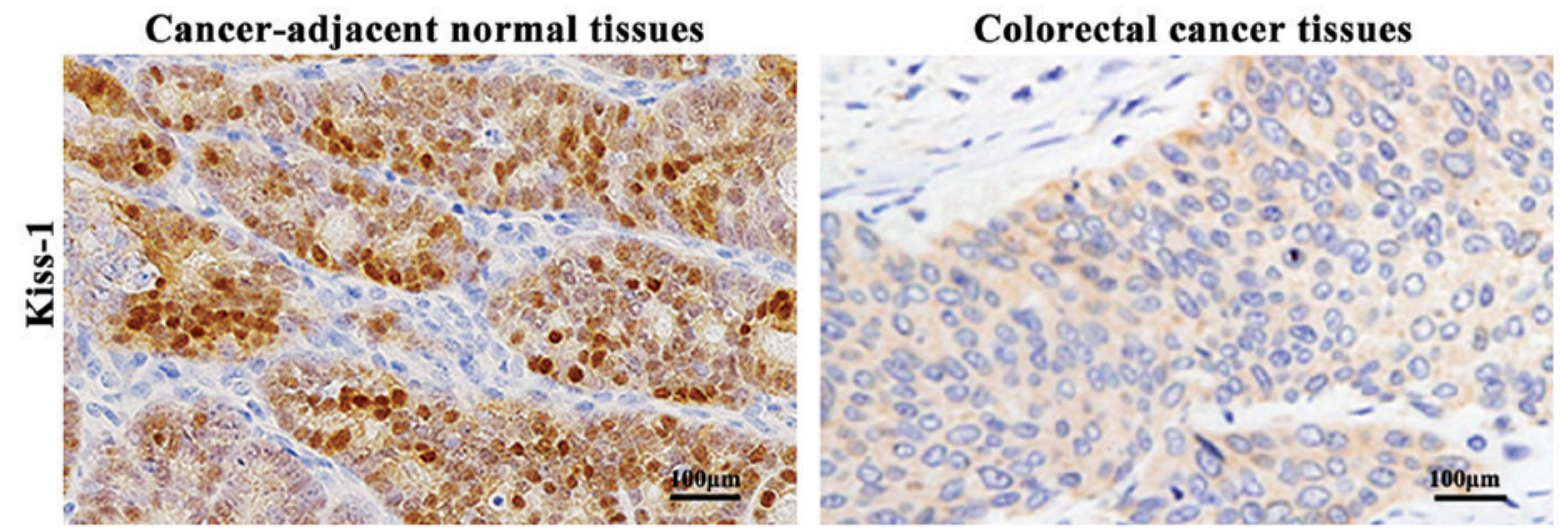

Figure 2. Detection of the expression of KiSS-1 proteins in tissues of patients by immunohistochemistry. The expression level of KiSS-1 in colorectal cancer tissues is significantly decreased compared with that in cancer-adjacent normal tissues.

0 points for positive cells $<5 \%, 1$ point for $5-25 \%, 2$ points for $26-50 \%$ and 3 points for $>51 \% ; 0$ points for basic colorlessness, 1 point for light yellow, 2 points for pale brown and 3 points for chocolate-brown. These scores were added, and $\leq 3$ points represented negative expression, while $>3$ points represented positive expression.

Relationship of the expression of KiSS-1 in the tumor tissues of patients with colorectal cancer with pathological parameters and the prognosis of patients. According to the expression level of KiSS-1 in colorectal cancer tissues, 56 patients with colorectal cancer were divided into the KiSS-1 positive and KiSS-1 negative expression groups. Clinicopathological parameters of patients were examined and the association between the expression of KiSS-1 and pathological parameters of patients was analyzed. The 56 patients were followed up after surgery for 5 years. The survival time was calculated from the first day after surgery, and the follow-up was carried out once a month.

Statistical treatment. Data were processed using Statistical Product and Service Solutions (SPSS) 17.0 software (IBM Corp., Armonk, NY, USA). Measurement data were expressed as mean \pm standard deviation, and t-test was used for comparisons between two groups. The $\chi^{2}$ test was used for intergroup comparisons of countable data. The univariate survival analysis was performed using Kaplan-Meier method. $\mathrm{P} \leq 0.05$ was considered to indicate a statistically significant difference.

\section{Results}

Detection of the expression of KiSS-1 in tumor tissues of patients with colorectal cancer by RT-qPCR. As shown in Fig. 1, the expression of KiSS-1 mRNA in colorectal cancer tissues was significantly decreased compared with that in cancer-adjacent normal tissues $(\mathrm{P}<0.01)$.

Detection of the expression of KiSS-1 in tumor tissue specimens of patients with colorectal cancer by immunohistochemistry. As shown in Fig. 2, immunohistochemistry results indicated that the positiveness of KiSS-1 proteins was manifested as light brown or dark brown precipitates in the cytoplasm. The expression levels of KiSS-1 proteins in colorectal cancer
Table II. Association of the abnormal expression of KiSS-1 and clinicopathological parameters of patients with colorectal cancer.

\begin{tabular}{|c|c|c|c|c|}
\hline \multirow[b]{2}{*}{$\begin{array}{l}\text { Clinicopathological } \\
\text { parameters }\end{array}$} & \multirow[b]{2}{*}{ Case } & \multicolumn{3}{|c|}{ KiSS-1 } \\
\hline & & $\begin{array}{l}\text { Negative } \\
\text { expression } \\
\text { (case, \%) }\end{array}$ & $\chi^{2}$ & P-value \\
\hline Sex & & & 0.12 & $>0.05$ \\
\hline Male & 32 & $24(75.00)$ & & \\
\hline Female & 24 & $17(70.83)$ & & \\
\hline Age (years) & & & 0.05 & $>0.05$ \\
\hline$\geq 50$ & 35 & $26(74.290$ & & \\
\hline$<50$ & 21 & $15(71.43)$ & & \\
\hline Tumor size $(\mathrm{cm})$ & & & 0.51 & $>0.05$ \\
\hline$\geq 5$ & 33 & $23(69.70)$ & & \\
\hline$<5$ & 23 & $18(78.26)$ & & \\
\hline Differentiation degree & & & 14.24 & $<0.01$ \\
\hline Low & 22 & $10(45.45)$ & & \\
\hline Moderate/high & 34 & $31(91.18)$ & & \\
\hline Invasion and metastasis & & & 12.63 & $<0.05$ \\
\hline Yes & 36 & $32(88.89)$ & & \\
\hline No & 20 & $9(45.00)$ & & \\
\hline Clinical staging & & & 10.36 & $<0.01$ \\
\hline I-II & 25 & $13(52.00)$ & & \\
\hline III-IV & 31 & $28(90.32)$ & & \\
\hline
\end{tabular}

tissues were significantly decreased compared with that in the cancer-adjacent normal tissues $(\mathrm{P}<0.01)$.

Results of the statistical analysis according to the standard of evaluation indicated that the positive expression rate of KiSS-1 proteins in colorectal cancer tissues was $26.79 \%$ (15/56), and the negative expression rate was $73.21 \%$ (41/56). The positive expression rate of KiSS-1 proteins in the cancer-adjacent normal tissues was $80.36 \%(45 / 56)$, and the negative expression rate was $19.64 \%$ (11/56). 


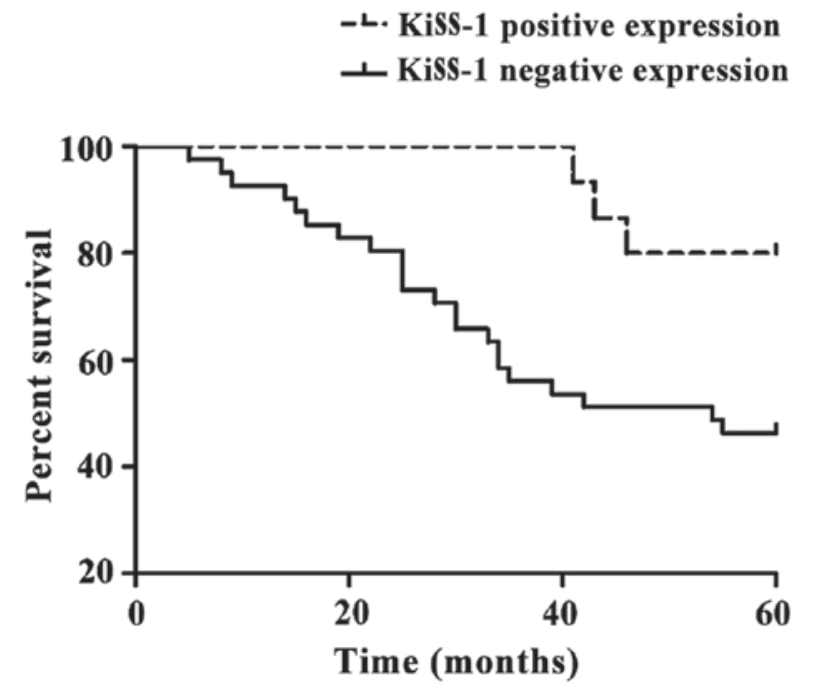

Figure 3. Expression of KiSS-1 and Kaplan-Meier survival curve of patients with colorectal cancer. Patients with negatively expressed KiSS-1 have worse prognosis than those with positively expressed KiSS-1.

Table III. Univariate survival analysis of the association between the expression of KiSS-1 and the overall survival rate of patients with colorectal cancer.

\begin{tabular}{|c|c|c|c|c|c|}
\hline Group & Case & $\begin{array}{c}\text { 5-year } \\
\text { survival } \\
\text { case }\end{array}$ & $\begin{array}{l}\text { 5-year } \\
\text { survival } \\
\text { rate }(\%)\end{array}$ & $\begin{array}{c}\text { Wald } \\
\text { (log-rank) }\end{array}$ & P-value \\
\hline KiSS-1 & & & & 5.36 & $<0.05$ \\
\hline Positive expression & 15 & 12 & 73.33 & & \\
\hline Negative expression & 41 & 19 & 48.78 & & \\
\hline
\end{tabular}

Association between the expression of KiSS-1 in tumor tissues of patients with colorectal cancer and clinicopathological parameters. According to the results of immunohistochemistry, patients with colorectal cancer were divided into the KiSS-1 positive and KiSS-1 negative expression groups, and the association between the expression of KiSS-1 in the tumor tissues of patients with colorectal cancer and clinicopathological parameters was examined. The results showed that the negative expression of KiSS-1 in tumor tissues of patients was correlated with tumor differentiation degree, invasion and metastasis as well as clinical staging (Table II).

Analysis of the survival condition and prognosis of patients. The 5-year follow up was statistically analyzed, and showed that of the 56 patients with colorectal cancer, 31 survived and 25 succumbed to the disease. The 5-year overall survival rate was $55.36 \%$ (31/56). Results of the Kaplan-Meier analysis of survival curves for colorectal cancer patients are shown in Fig. 3. Patients with negatively expressed KiSS-1 had worse prognosis. Results of the univariate survival analysis are shown in Table III. KiSS-1 significantly affected the overall survival rate of colorectal cancer, which was an independent factor affecting the survival of patients with colorectal cancer $(\mathrm{P}<0.05)$.

\section{Discussion}

Colorectal cancer is a common malignant tumor of the digestive tract with a high metastatic rate, whose incidence ranks second in female tumors and third in male tumors worldwide (1).

In recent years, the KiSS-1 gene has become a hot spot in tumor research. Previous findings have shown that KiSS-1 proteins can inhibit tumor cell proliferation and invasion and induce tumor cell apoptosis (14). The coding product of KiSS-1 genes is polypeptide with the same length as that of 54 amino acids, which can bind specifically to GPR54 or AXOR12. After binding to GPR54, polypeptide induces phosphatidylinositol 4,5-bisphosphate (PIP2) hydrolysis to elevate the intracellular calcium concentration, thus activating intracellular signaling pathways to play roles in inhibiting cell proliferation and differentiation $(15,16)$. Stafford et al showed that proteins encoded by KiSS-1 bind to GPR54 to activate phospholipase $\mathrm{C}$, producing the second messenger inositol trisphosphate (IP3) and diglycerides in cells to inhibit cell proliferation and promote cell apoptosis (8). Other findings have shown that KiSS-1 can suppress the invasion and metastasis of tumor cells, and its mechanism is mainly to downregulate the expression of matrix metallopeptidase-9 (MMP-9) in order to carry out its roles (17).

The present study aimed to study the expression of KiSS-1 in tissues of colorectal cancer patients and its effects on pathological parameters and the prognosis of patients with colorectal cancer. In the present study, RT-qPCR was used to detect the expression of KiSS-1 mRNA in tumor tissues and cancer-adjacent normal tissues of patients with colorectal cancer. The results showed that the transcription level of KiSS-1 mRNA in the tissues of patients with colorectal cancer was significantly lower than that in the cancer-adjacent normal tissues. The results of immunohistochemistry also confirmed that the expression level of KiSS-1 proteins in tissues of patients with colorectal cancer was significantly decreased compared to that in cancer-adjacent normal tissues. In order to determine the association between its expression and the pathological parameters of patients, statistical analysis was conducted, which indicated that the negative expression of KiSS-1 in the tumor tissues of patients was correlated with the degree of tumor differentiation, invasion and metastasis as well as clinical staging. The univariate Kaplan-Meier survival analysis was used to assess the effect of KiSS-1 expression on the 5-year overall survival rate of patients. The results showed that KiSS-1 significantly affected the overall survival of colorectal cancer, and patients with lowly expressed KiSS-1 have lower 5-year survival rate and worse prognosis.

Dhar et al found the presence of lowly expressed KiSS-1 genes in tissues of patients with gastric cancer, and KiSS-1 is closely associated with the metastasis of gastric cancer (18). Studies of Masui et al suggested that the expression of KiSS-1 genes in pancreatic cancer tissues was significantly lower than that in normal tissues, and the low expression of KiSS-1 genes may be associated with the metastasis and staging of pancreatic cancer (19). Results of the aforementioned studies are consistent with those of the current study. In the present study, the expression of KiSS-1 was confirmed to be downregulated in the tumor tissues of patients with colorectal cancer. It was 
also shown that the expression of KiSS-1 was correlated with the degree of tumor differentiation, invasion and metastasis, clinical staging and prognosis.

In summary, KiSS-1 is lowly expressed in tumor tissues of colorectal cancer patients, which is closely associated with the occurrence and development of colorectal cancer, the degree of differentiation, invasion and metastasis, as well as clinical staging. KiSS-1 also affects the 5-year survival rate of patients. Patients with lowly expressed KiSS-1 have a lower 5-year survival rate. Consequently, the expression of KiSS-1 of tumor tissues of patients can be used as a reference factor for the prognosis estimation for colorectal cancer patients.

\section{References}

1. Chen W, Zheng R, Baade PD, Zhang S, Zeng H, Bray F, Jemal A, Yu XQ and He J: Cancer statistics in China, 2015. CA Cancer J Clin 66: 115-132, 2016

2. Chen W, Zheng R, Zhang S, Zhao P, Zeng H and Zou X: Report of cancer incidence and mortality in China, 2010. Ann Transl Med 2: 61, 2014.

3. Slipicevic A, Holm R, Emilsen E, Ree Rosnes AK, Welch DR, Mælandsmo GM and Flørenes VA: Cytoplasmic BRMS1 expression in malignant melanoma is associated with increased disease-free survival. BMC Cancer 12: 73-79, 2012.

4. Xie J, Xiang DB, Wang H, Zhao C, Chen J, Xiong F, Li TY and Wang XL: Inhibition of Tcf-4 induces apoptosis and enhances chemosensitivity of colon cancer cells. PLoS One 7: e45617, 2012.

5. Elferink MA, de Jong KP, Klaase JM, Siemerink EJ and de Wilt JH: Metachronous metastases from colorectal cancer: A population-based study in North-East Netherlands. Int J Colorectal Dis 30: 205-212, 2015.

6. Samant RS, Seraj MJ, Saunders MM, Sakamaki TS, Shevde LA, Harms JF, Leonard TO, Goldberg SF, Budgeon L, Meehan WJ, et al: Analysis of mechanisms underlying BRMS1 suppression of metastasis. Clin Exp Metastasis 18: 683-693, 2000.

7. Lee JH, Miele ME, Hicks DJ, Phillips KK, Trent JM, Weissman BE and Welch DR: KiSS-1, a novel human malignant melanoma metastasis-suppressor gene. J Natl Cancer Inst 88: 1731-1737, 1996

8. Stafford LJ, Xia C, Ma W, Cai Y and Liu M: Identification and characterization of mouse metastasis-suppressor KiSS1 and its G-protein-coupled receptor. Cancer Res 62: 5399-5404, 2002.

9. Masui T, Doi R, Mori T, Toyoda E, Koizumi M, Kami K, Ito D, Peiper SC, Broach JR, Oishi S, et al: Metastin and its variant forms suppress migration of pancreatic cancer cells. Biochem Biophys Res Commun 315: 85-92, 2004.
10. Guan-Zhen Y, Ying C, Can-Rong N, Guo-Dong W, Jian-Xin Q and Jie-Jun W: Reduced protein expression of metastasis-related genes (nm23, KISS1, KAI1 and p53) in lymph node and liver metastases of gastric cancer. Int J Exp Pathol 88: 175-183, 2007.

11. Cho SG, Li D, Stafford LJ, Luo J, Rodriguez-Villanueva M, Wang Y and Liu M: KiSS1 suppresses TNFalpha-induced breast cancer cell invasion via an inhibition of RhoA-mediated NF-kappaB activation. J Cell Biochem 107: 1139-1149, 2009.

12. Cebrian V, Fierro M, Orenes-Piñero E, Grau L, Moya P, Ecke T, Alvarez M, Gil M, Algaba F, Bellmunt J, et al: KISS1 methylation and expression as tumor stratification biomarkers and clinical outcome prognosticators for bladder cancer patients. Am J Pathol 179: 540-546, 2011.

13. Siegel RL, Miller KD, Fedewa SA, Ahnen DJ, Meester RGS, Barzi A and Jemal A: Colorectal cancer statistics, 2017. CA Cancer J Clin 67: 177-193, 2017.

14. Mandai M, Konishi I, Kuroda H, Nanbu K, Matsushita K, Yura Y, Hamid AA and Mori T: Expression of abnormal transcripts of the FHIT (fragile histidine triad) gene in ovarian carcinoma. Eur J Cancer 34: 745-749, 1998.

15. Kotani M, Detheux M, Vandenbogaerde A, Communi D, Vanderwinden JM, Le Poul E, Brézillon S, Tyldesley R, SuarezHuerta N, Vandeput F, et al: The metastasis suppressor gene KiSS-1 encodes kisspeptins, the natural ligands of the orphan G protein-coupled receptor GPR54. J Biol Chem 276: 34631-34636, 2001.

16. Muir AI, Chamberlain L, Elshourbagy NA, Michalovich D, Moore DJ, Calamari A, Szekeres PG, Sarau HM, Chambers JK, Murdock P, et al: AXOR12, a novel human G protein-coupled receptor, activated by the peptide KiSS-1. J Biol Chem 276: 28969-28975, 2001.

17. Ohtaki T, Shintani Y, Honda S, Matsumoto H, Hori A, Kanehashi K, Terao Y, Kumano S, Takatsu Y, Masuda Y, et al: Metastasis suppressor gene KiSS-1 encodes peptide ligand of a G-protein-coupled receptor. Nature 411: 613-617, 2001.

18. Dhar DK, Naora H, Kubota H, Maruyama R, Yoshimura H, Tonomoto Y, Tachibana M, Ono T, Otani H and Nagasue N: Downregulation of KiSS-1 expression is responsible for tumor invasion and worse prognosis in gastric carcinoma. Int J Cancer 111: 868-872, 2004.

19. Masui T, Doi R, Mori T, Toyoda E, Koizumi M, Kami K, Ito D, Peiper SC, Broach JR, Oishi S, et al: Mtastin and its variant forms suppress migration of pancreatic cancer cells. Biochem Biophys Res Commun 315: 85-92, 2004.

This work is licensed under a Creative Commons Attribution-NonCommercial-NoDerivatives 4.0 International (CC BY-NC-ND 4.0) License. 